\title{
A SUSTAINABILITY APPROACH: INTEGRATION OF A MICROENCAPSULATED PHASE CHANGE MATERIAL TO A RECYCLED PES NONWOVEN FABRIC TO DEVELOP A HEAT STORING RECYCLED MATERIAL
}

DOI: 10.35530/TT.2021.01

\author{
E.G. Saraç ${ }^{1 *}$, E. Öner ${ }^{1}$, M.V. Kahraman ${ }^{2}$
}

\author{
${ }^{1}$ Department of Textile Engineering, Faculty of Technology, Marmara University, Turkey \\ (E-mail: egsarac@gmail.com, eoner@marmara.edu.tr) \\ ${ }^{2}$ Department of Chemistry, Faculty of Arts and Sciences, Marmara University, Turkey \\ (E-mail: mvezir@marmara.edu.tr)
}

\begin{abstract}
Phase change materials (PCMs) are thermal energy storing materials which are adopted in various industries including textiles. They provide temperature regulation by absorbing the heat from the ambiance or releasing the latent heat that they store. PCMs are widely integrated into textiles in microencapsulated form where the core PCM is covered by the microcapsule shell and protected during phase change. This form also provides a higher thermal conductivity. In this work, a blend of organic coconut oil and n-octadecane were used as phase change material in core, and melamine formaldehyde was used as shell material to develop microencapsulated PCM for heat storage. The microcapsules were produced by using in situ polymerization method. The developed microcapsules (MPCMs) were integrated to a recycled PES (polyester) nonwoven fabric, generated from PET (polyethylene terephthalate) fibres, and manufactured by combing and needle punching technique. The MPCMs were implemented to the fabric by coating method. The core PCM, MPCM, and the coated nonwoven fabric were assessed by Differential Scanning Calorimetry (DSC), Scanning Electron Microscopy (SEM) and Fourier Transform Infrared Spectroscopy (FT-IR). SEM results indicated that spherical and uniform microcapsules were obtained with a particle size of 3-9 $\mu \mathrm{m}$. DSC results revealed that MPCM and the MPCM coated nonwoven fabric possessed a remarkable melting enthalpy of $111 \mathrm{~J} / \mathrm{g}$ and $30.9 \mathrm{~J} / \mathrm{g}$, respectively at peak melting temperatures of $28.1^{\circ} \mathrm{C}$ and $27.4^{\circ} \mathrm{C}$.
\end{abstract}

Keywords: coconut oil, heat storage, microencapsulation, phase change material, sustainability

\section{INTRODUCTION}

The use of thermo-regulative textiles has been growing in several areas such as home textiles, bedding, protective textiles, and active wear. Phase change materials (PCMs) provide thermal regulation property by storing or releasing the heat at a specific temperature range where the phase change takes place. Microencapsulation is a way of packaging the PCM which prevents the leakage of the core substance on textile material in liquid state during phase change, and ensures chemical durability as well as increased area of heat transfer. PCMs are usually incorporated to fibre or fabric in microencapsulated form [1]. PCMs which 
are used to be incorporated in textiles are linear long chain hydrocarbons, polyethylene glycols, fatty acids and their blends [1,2]. PCMs with melting points between $15^{\circ} \mathrm{C}$ and $35^{\circ} \mathrm{C}$ are suggested as the most effective PCMs for cooling in textile and clothing [1]. Recent studies focused on to generate novel encapsulated PCMs [5-7] and to develop new design PCM-incorporated textiles with a high thermo-regulating performance. Lin et al. studied in thermo-regulating glove design as a protective wear by integrating microencapsulated PCMs to a fabric layer of the glove by coating application [8]. Borreguero et al. worked on the use of PCMs in footwear by doping the microcapsules with carbon nanofibers (CNFs) on various fabric surfaces, formed composites, and analysed the thermal energy storage and the thermal insulation properties of the developed composites [9]. Saraç et al. applied the microencapsulated PCMs to a medical textile by coating on to a nonwoven fabric layer and then confining the material within the layers of the textile to create a thermo-regulation property [10].

In this study, novel microcapsules containing a blend of organic coconut oil and noctadecane in core were synthesized by in situ polymerization method [3,5] and then applied on a recycled PES nonwoven fabric by coating to obtain a sustainable thermo-regulating heat storing material which can be used as a textile substrate in geotextiles, medical textiles, or automotive textiles [11]. Thermal performance of the core PCM, MPCM and the treated fabric were tested and assessed.

\section{GENERAL INFORMATION}

\subsection{Materials}

100\% Organic Coconut Oil (Sri Lanka origin, supplied by LifeCo Company) and crystalline mass/melt n-octadecane (\%98, Alfa Aesar) were used as PCM core materials. Melamine (99\% pure) from Aldrich, formaldehyde (37\% aqueous solution, Merck) were used as shell materials. Sodium dodecyl sulphate (SDS, Fluka Chemika) was used as emulsifier, Melateks 700 containing methylol was used as crosslinker for the melamine formaldehyde shell, and ammonium chloride (extra pure, Riedel-de Haen) was used as nucleating agent in encapsulation reactions. Triethanolamine (99\%, Merck) was used to adjust the $\mathrm{pH}$ in reactions. For coating treatment, chemicals from Organik Kimya (Turkey) were used in the coating solution. Dispersant K 850 was used as an anionic dispersing agent, Antifoam S6010 was used to prevent foaming in the coating solution, polyurethane based Orgaresin PN 50 was used as binder and Orgafix DX New was used as the fixator in the coating treatment. Recycled PES nonwoven fabric, which was made of $100 \%$ recycled PET fibers and manufactured by combing- needle punching technique, was supplied by Hassan Tekstil A.S., Turkey.

\subsection{Methods}

A blend of organic coconut oil and n-octadecane (30\% organic coconut oil and $70 \% \mathrm{n}$ octadecane by weight) was microencapsulated in melamine formaldehyde shell by using in situ polymerization method [5]. The encapsulation process comprised preparation of prepolymer solution of melamine and formaldehyde, preparation of oil in water emulsion, and the synthesis of microcapsules [3,5]. The pre-polymer solution was prepared by dissolving $6 \mathrm{~g}$ of melamine and $30 \mathrm{~mL}$ of formaldehyde in $30 \mathrm{~mL}$ of distilled water with magnetic stirring at 
$750 \mathrm{rpm}$ at $70{ }^{\circ} \mathrm{C}$. The $\mathrm{pH}$ of the solution was adjusted to 9 by the addition of triethanolamine. As the solution became clear, $1 \mathrm{~g}$ of melamine and $10 \mathrm{ml}$ distilled water were added and dissolved. For the emulsion preparation, $12 \mathrm{~g}$ of organic coconut oil and $28 \mathrm{~g}$ of n-octadecane were emulsified in $300 \mathrm{~mL}$ distilled water by the addition of $4 \mathrm{~g}$ SDS as an emulsifier and 1.5 g Melateks 700 as a cross-linker. The emulsion was mechanically stirred at the rate of 2700 rpm at $50{ }^{\circ} \mathrm{C}$ for $3 \mathrm{~h}$. The $\mathrm{pH}$ of the emulsion solution was adjusted to 4 by the addition of acetic acid dropwise. Then, the pre-polymer solution was added dropwise to the emulsion solution while stirring at $600 \mathrm{rpm} .1 \mathrm{~g}$ of ammonium chloride was added to the solution as nucleating agent. The encapsulation reaction was carried out at $60{ }^{\circ} \mathrm{C}$ for $100 \mathrm{~min}$. The reaction was terminated by adjusting the $\mathrm{pH}$ to 8.5 . The microcapsules were filtered and then washed repeatedly by $30 \%$ ethanol solution, then dried at $50{ }^{\circ} \mathrm{C}$ for $24 \mathrm{~h}$.

The fabricated microcapsules were integrated to recycled PES nonwoven fabric by coating application (figure 1). The coating solution was prepared according to the recipe given in table 1 . The coating paste was applied on the nonwoven surface. Following that, the coated fabric was dried for $15 \mathrm{~min}$ at $110^{\circ} \mathrm{C}$ and cured for $5 \mathrm{~min}$ at $160^{\circ} \mathrm{C}$.

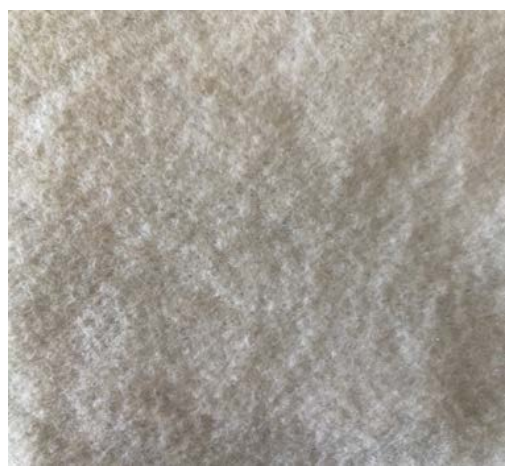

a

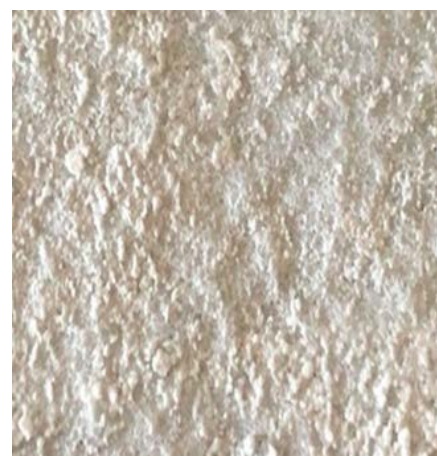

b

Figure 1. Images of: $a$ - untreated fabric; $b$ - treated fabric

Table 1. Coating recipe of MPCM

\begin{tabular}{|c|c|c|}
\hline Name of the contents & Weight (g) & \% in total wt. \\
\hline MPCM & 8 & 16.7 \\
\hline Dispersant K 850 & 0.25 & 0.5 \\
\hline Antifoam S 6010 & 0.25 & 0.5 \\
\hline Orgaresin PN 50 & 16 & 33.3 \\
\hline Orgafix DX New & 1.6 & 3.3 \\
\hline Distilled water & 19 & 39.6 \\
\hline Orgal M 420 & 2.9 & 6.0 \\
\hline Total & 48 & 100 \\
\hline
\end{tabular}

The chemical composition of the core PCM and the MPCM were characterized by FT-IR (figure 2). The surface morphology of the MPCM and the treated fabric were examined by SEM analysis (figure 3). The heat storage performances of the core PCM, the MPCM and the coated nonwoven fabric were assessed by DSC measurements (figures 4 and 5). The encapsulation ratio (R\%), which indicates the core content of the MPCM, 
was calculated by equation 1 and the coating add-on\% was calculated by equation 2 .

$$
\mathrm{R}(\%)=\left(\Delta \mathrm{H}_{\mathrm{m}, \mathrm{MPCM}} / \Delta \mathrm{H}_{\mathrm{m}, \mathrm{PCM}}\right) \times 100
$$

Add-on (\%) $=[($ Dry fabric weight after coating - Dry fabric weight before coating $) /$

Dry fabric weight before coating] x 100

The coated and the uncoated fabric thicknesses were also tested. Thermographic temperatures of the untreated and the treated fabrics were measured at the ambient temperature of $28.5^{\circ} \mathrm{C}$, on a temperature-controlled oven at $50-70^{\circ} \mathrm{C}$ (table 2) during heating and cooling processes.

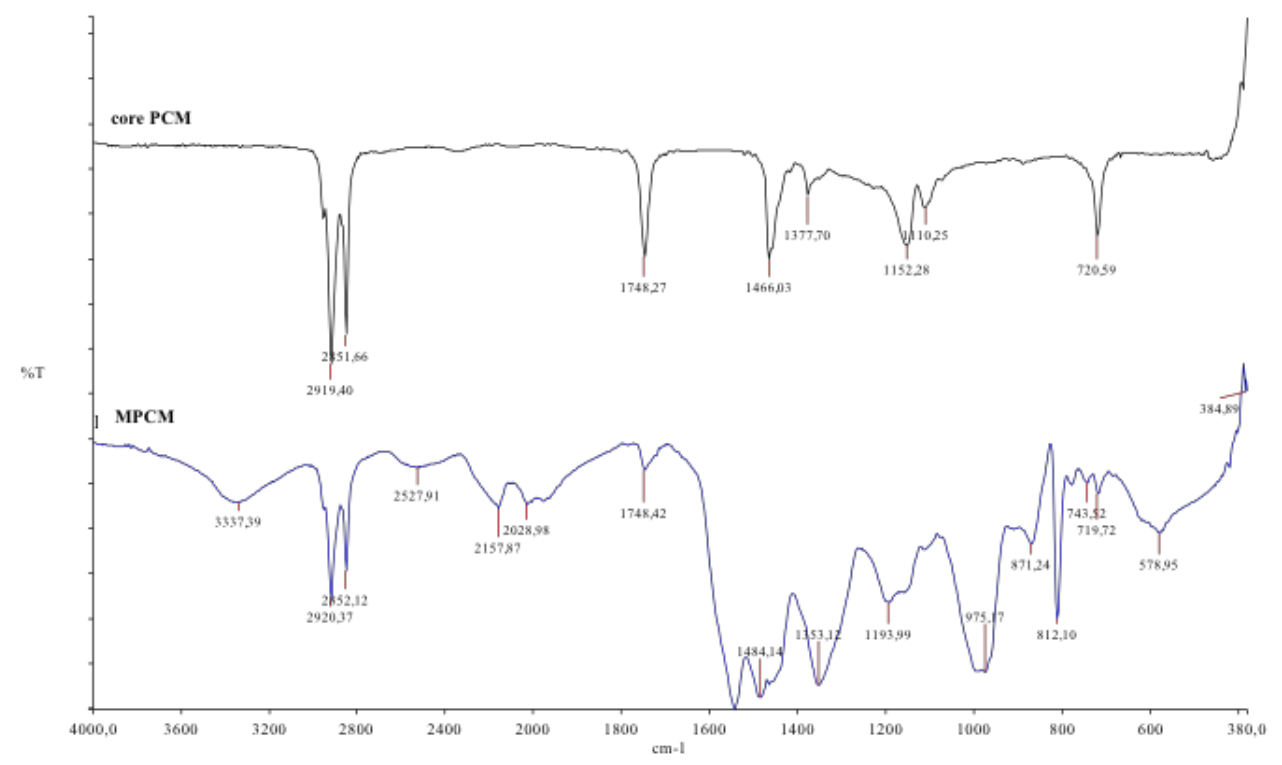

Figure 2. FT-IR Spectra of the core PCM and the MPCM
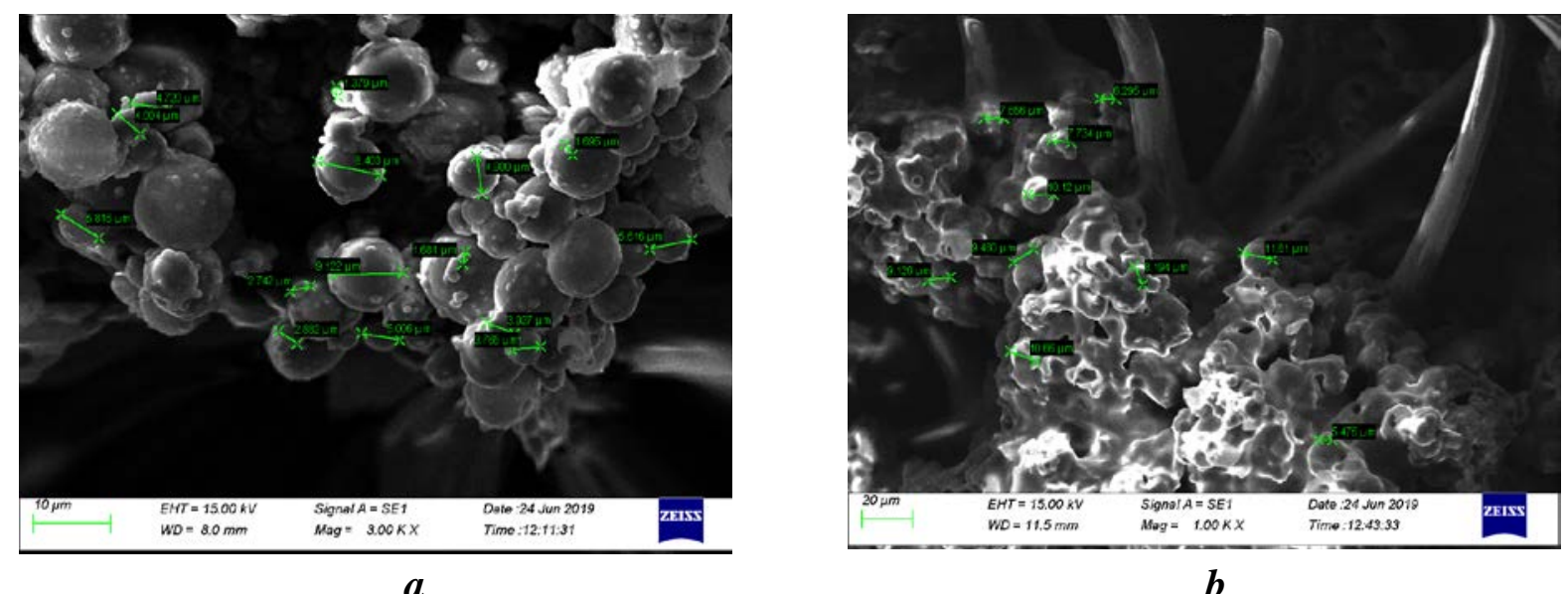

b

Figure 3. SEM images of: a - MPCM; b - MPCM coated fabric 


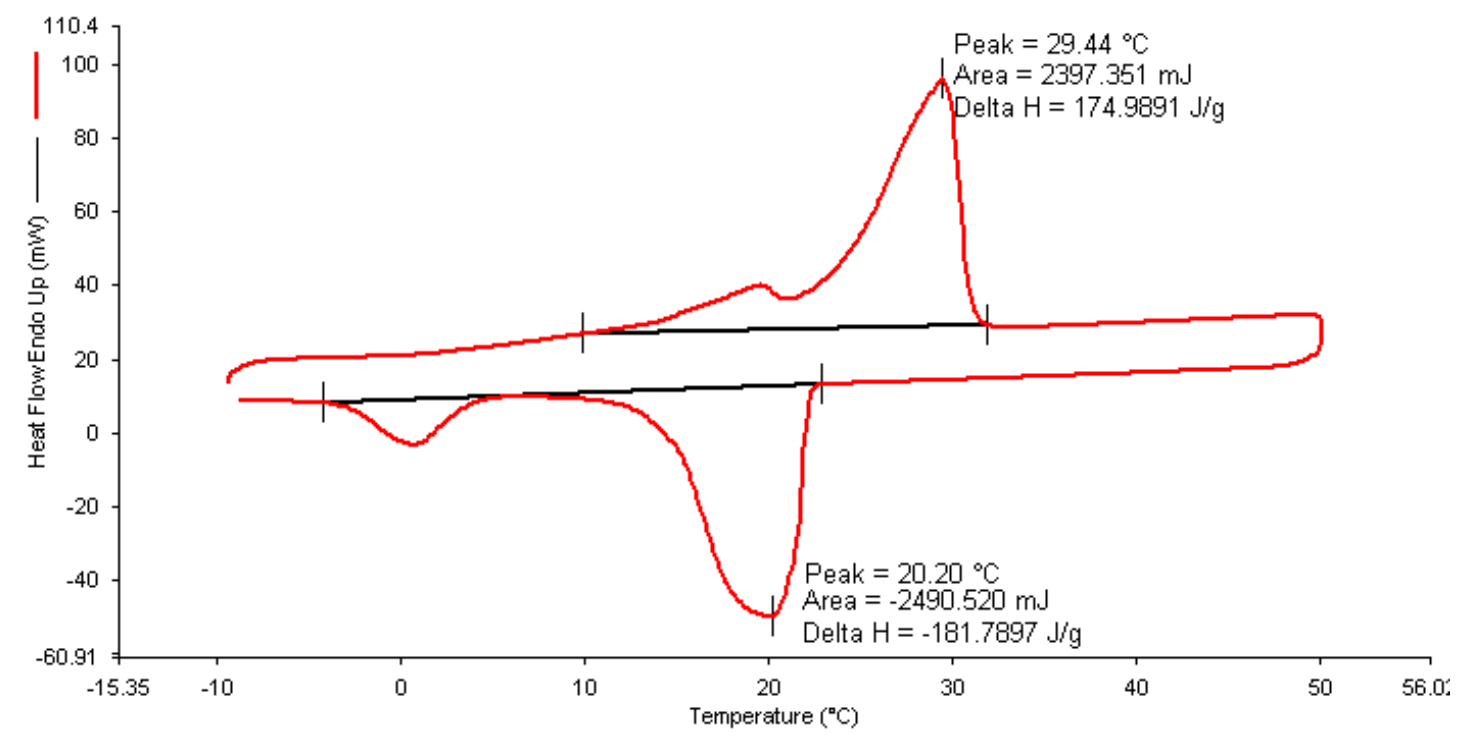

Figure 4. DSC curve of the core PCM

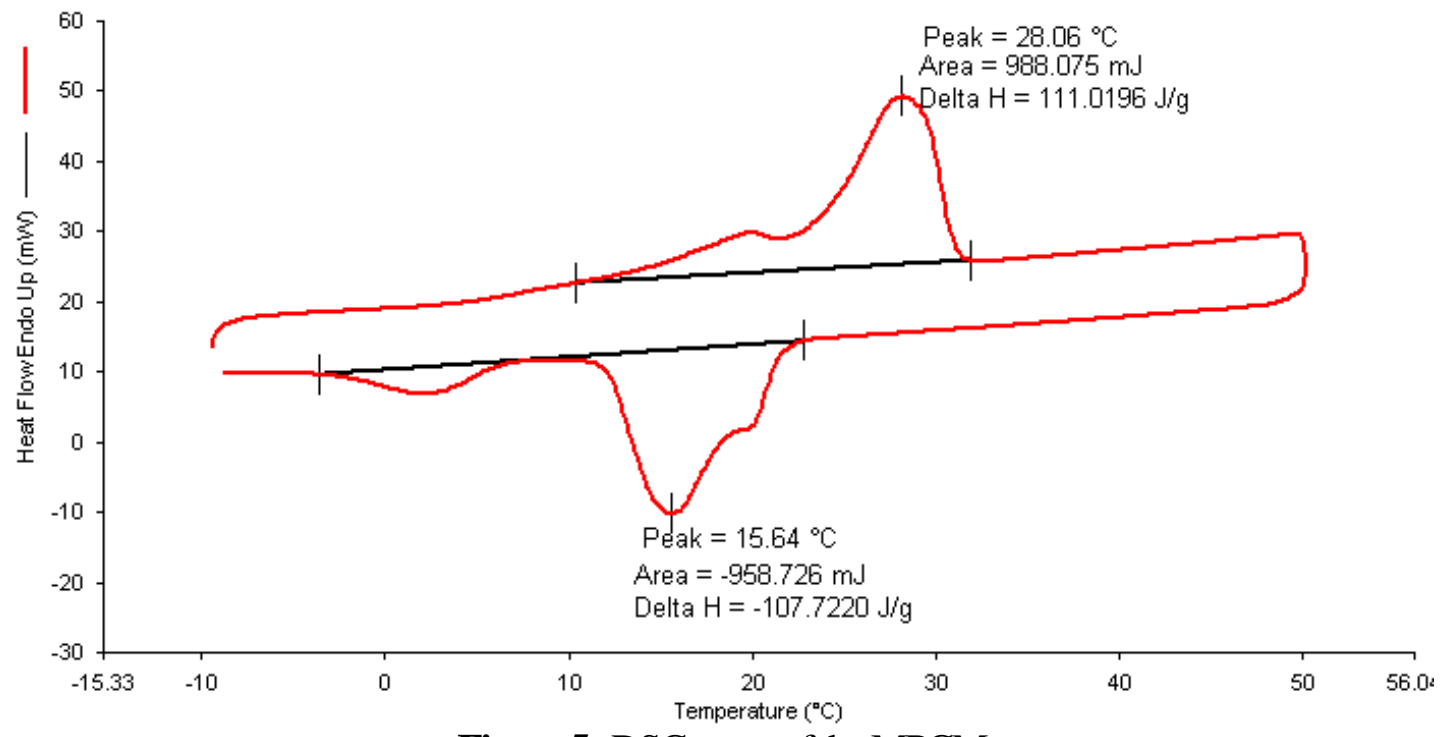

Figure 5. DSC curve of the MPCM 
Table 2. Thermographic images of untreated and treated fabric samples

\begin{tabular}{|c|c|c|c|}
\hline Time & Untreated Sample & Treated Sample & Temperature Colour Scale \\
\hline \multirow{2}{*}{$\begin{array}{c}\text { Heating } \\
0 \mathrm{~s}\end{array}$} & & & \multirow{3}{*}{$950^{\circ} \mathrm{C}$} \\
\hline & $\mathrm{T}_{\mathrm{r}}=55.7^{\circ} \mathrm{C}$ & $\mathrm{T}_{\mathrm{i}}=55.6^{\circ} \mathrm{C}$ & \\
\hline \multirow{2}{*}{$\begin{array}{l}\text { Heating } \\
5 \mathrm{~min}\end{array}$} & 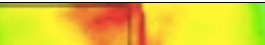 & \begin{tabular}{l|l|}
$x+1$ \\
\end{tabular} & \\
\hline & $\mathrm{T}_{\mathrm{r}}=59.1^{\circ} \mathrm{C}$ & $\mathrm{T}_{\mathrm{i}}=58.3^{\circ} \mathrm{C}$ & -800 \\
\hline \multirow{2}{*}{$\begin{array}{c}\text { Cooling } \\
0 \mathrm{~s}\end{array}$} & & & \multirow{3}{*}{$\begin{array}{l}-60.0 \\
-500\end{array}$} \\
\hline & $\mathrm{T}_{\mathrm{t}}=39.5^{\circ} \mathrm{C}$ & $\mathrm{T}_{\mathrm{i}}=48.6^{\circ} \mathrm{C}$ & \\
\hline \multirow{2}{*}{$\begin{array}{c}\text { Cooling } \\
60 \mathrm{~s}\end{array}$} & & & \\
\hline & & & \multirow{3}{*}{$\begin{array}{l}-40.0 \\
-30.0\end{array}$} \\
\hline \multirow{3}{*}{$\begin{array}{c}\text { Cooling } \\
120 \mathrm{~s}\end{array}$} & $\mathrm{~T}_{\mathrm{r}}=31.1^{\circ} \mathrm{C}$ & $\mathrm{T}_{\mathrm{i}}=34.1^{\circ} \mathrm{C}$ & \\
\hline & & & \\
\hline & $\mathrm{T}_{\mathrm{r}}=30.3^{\circ} \mathrm{C}$ & $\mathrm{T}_{\mathrm{i}}=31.7^{\circ} \mathrm{C}$ & $250^{\circ} \mathrm{C}$ \\
\hline
\end{tabular}

\section{CONCLUSIONS}

The MPCMs, which contain a blend of coconut oil and n-octadecane in core and melamine formaldehyde in shell, were produced by in situ polymerization successfully. The MPCMs were integrated to the recycled PES nonwoven fabric by coating application.

FT-IR spectra of the core PCM and the MPCM was given in figure 2. The absorption peak at $3333 \mathrm{~cm}^{-1}$ was attributed to $\mathrm{O}-\mathrm{H}$ bending vibration of the melamine formaldehyde microcapsule crosslinked with the cross-linker containing methylol. The peaks placed at $2920 \mathrm{~cm}^{-1}$ and $2852 \mathrm{~cm}^{-1}$ were assigned to C-H bond stretching vibrations. The absorption peak at $1748 \mathrm{~cm}^{-1}$ was attributed to $\mathrm{C}=\mathrm{O}$ stretching vibration of the microcapsule and the fatty acid. The peaks placed at approximately $1540 \mathrm{~cm}^{-1}$ and 1490 $\mathrm{cm}^{-1}$ were assigned to $\mathrm{C}=\mathrm{N}$ and $\mathrm{C}-\mathrm{N}$ stretching vibrations of melamine formaldehyde [3,5]. FT-IR results confirmed that the melamine formaldehyde microcapsule was formed successfully. SEM images (figure 3) revealed that spherical and uniform microcapsules were obtained with a particle size of 3-9 $\mu \mathrm{m}$. The SEM image of the treated fabric illustrated that the microcapsules were densely and uniformly distributed on the fabric surface with the coating binder. The DSC analyses (figures 4 and 5) showed that the core PCM and the MPCM had significantly high melting enthalpies of $175 \mathrm{~J} / \mathrm{g}$ and $111 \mathrm{~J} / \mathrm{g}$ at peak melting temperatures of $29.4^{\circ} \mathrm{C}$ and $28.1^{\circ} \mathrm{C}$, respectively. The encapsulation ratio of the MPCM was calculated as $63.4 \%$ (equation 1). The DSC results revealed that the MPCM treated fabric possessed a $30.9 \mathrm{~J} / \mathrm{g}$ latent heat of fusion at the peak temperature of $27.4^{\circ} \mathrm{C}$ which is close to human skin comfort temperature [12]. The latent heat storage performance was found to be remarkably high comparing to literature [3-5]. The coating add-on was calculated as $171 \%$ due to the light weight structure of the nonwoven fabric. The thickness of the untreated and the MPCM treated fabric were measured as $1.84 \mathrm{~mm}$ and $2.22 \mathrm{~mm}$, respectively. Thermographic images (table 2) of the untreated and the treated fabrics indicated that, the 
MPCM treated fabric absorbed and stored the heat more in the heating process due to its PCM content, and the treated fabric temperature decreased more slowly comparing to the untreated one.

This experimental work advanced that the recycle PES nonwoven fabric gained a significant latent heat of fusion capacity after MPCM treatment, which is a reusable energy to regulate the temperature. The study suggests a novel application for nonwoven fabrics which can be used to develop a thermo-regulative filling material for bedding, geotextiles, home textiles, or automotive textiles. It also contributes to the sustainability of textiles by upcycling a recycled PES nonwoven fabric to a heat storing material. It is possible to carry out this study to an industrial scale.

\section{ACKNOWLEDGEMENTS}

The authors gratefully acknowledge the Grant FEN-C-DRP-200318-0117 by the Scientific Research Project Unit (BAPKO) of Marmara University.

\section{REFERENCES}

[1] Mondal, S., Phase change materials for smart textiles-an overview, In: Appl Therm Eng, 2008, 28, 1536-1550

[2] Sar1er, N., Önder, E., Organic phase change materials and their textile applications-an overview, In: Thermochim Acta, 2012, 540, 7-60

[3] Saraç, E.G., Öner, E., Kahraman, M.V., Microencapsulated organic coconut oil as a natural phase change material for thermo-regulating cellulosic fabrics, In: Cellulose, 2019, 26, 8939-8950

[4]Karthikeyan, M., Ramachandran, T., Sundaram, O.L.S., Synthesis, characterization, and development of thermally enhanced cotton fabric using nanoencapsulated phase change materials containing paraffin wax, In: J Text Inst, 2014, 105, 1279-1286

[5] Saraç, E.G., Development of thermo-regulating smart textiles and investigation of their performance properties, Doctoral Thesis, 2020

[6] Ruiz-Calleja, T., Bonet-Aracil, M., Gispert-Paya, J., Bou-Belda, E., Analysis of the influence of graphene and phase change microcapsules on thermal behavior of cellulosic fabrics, In: Materials Today Communications, 2020, 25, 101557

[7] Skurkyte-Papieviene, V., Abraitiene, A., Sakauskaite, A., Rubeziene, V., Baltusnikaite-Guzaitiene, J., Enhancement of the thermal performance of the paraffin-based microcapsules intended for textile applications, In: Polymers, 2021, 13, 1120

[8] Lin, S.H., Chang, C.P., Lynn, M., Ashdown, S.P., Exploring phase change materials in gloves to regulate body temperature, Conference paper, ICDHS Taipei, 2016. 214-217

[9] Borreguero, A.M., Talavera, B., Rodriguez, J.F., Valverde, J.L., Gonzales, J.L., Carmona, M., Enhancing the thermal comfort of fabrics for the footwear industry, In: Textile Research Journal, 2013, 83, 16, 1754-1763

[10] Saraç, E.G., Öner, E., Kahraman M.V., Developing a thermo-regulative system for nonwoven textiles using microencapsulated organic coconut oil, In: Journal of Industrial Textiles, 2020, https://doi.org/10.1177/1528083720921490

[11] Iqbal, K., Khan, A., Sun, D., Ashraf, M., Rehman, A., Safdar, F., Basit, A., Maqsood, H.S., Phase change materials, their synthesis and application, in textiles- a review, In: Journal of the Textile Institute, 2019, 110, 1, 1-14

[12] Erkan, G., Enhancing the thermal properties of textiles with phase change materials, In: Research Journal of Textile and Apparel, 2004, 8, 2 